\title{
Utilização de redes sociais educativas em projeto de pesquisa na universidade
}

\author{
Márcio Pedro C. P. de Queiroz ${ }^{1}$, Cecilio Ricardo de C. Bastos² \\ 1Programa de Pós-Graduação Mestrado em Educação, Cultura e Territórios Semiáridos \\ - Universidade do Estado da Bahia (UNEB) - Juazeiro, BA - Brasil \\ 2Programa de Pós-Graduação Mestrado em Educação, Cultura e Territórios Semiáridos \\ - Universidade do Estado da Bahia (UNEB) - Juazeiro, BA - Brasil \\ marciopataro77@gmail.com, cecilioricardoegmail.com
}

\begin{abstract}
The use of social networks has provided educational decentralization of referrals in teaching and learning contexts. Currently, using this type of tool is no longer conditional on the complex technical knowledge, equipment acquisition, hosting services etc. The article seeks to present a networked learning experience developed with journalism students integrating Research Project of the Universidade do Estado da Bahia.
\end{abstract}

Resumo. A utilização de redes sociais educativas tem proporcionado a descentralização dos encaminhamentos nos contextos de ensino $e$ aprendizagem. Atualmente, o uso desse tipo de ferramenta não está mais condicionado à conhecimentos técnicos complexos, aquisição de equipamentos, serviços de hospedagem etc. $O$ artigo busca apresentar uma experiência de aprendizagem em rede desenvolvida com os discentes de Jornalismo em Multimeios que integram Projeto de Pesquisa da Universidade do Estado da Bahia.

\section{Considerações sobre redes sociais educativas}

Com o surgimento da Internet a comunicação mundial em suas diversas áreas passou por inúmeras transformações. A velocidade, o fluxo e a troca da informação e do conhecimento entre organizações e indivíduos é um fator marcante promovido por essa grande rede. No século XXI aplicabilidade da internet nos variados campos do conhecimento é tema constante, discutido em academias e eventos. Nesse contexto as redes sociais educativas têm gerado discussões atrativas e consideráveis avanços.

A rede social se baseia nas relações entre humanos que estejam interagindo em causa própria, em defesa do outro ou até mesmo de uma entidade, mediadas ou não por máquinas. Recuero (2009) define redes sociais como "uma metáfora para observar os padrões de conexão de um grupo social, a partir das conexões estabelecidas entre os diversos atores" (p. 24). Ressaltamos a abordagem de que as redes sociais se caracterizam pela relação entre pessoas de um mesmo espaço ou não, sendo que todos interagem através de seus interesses. Para Marteleto (2010) "o conceito de redes sociais leva a uma compreensão da sociedade a partir dos vínculos relacionais entre os indivíduos, os quais reforçariam suas capacidades de atuação, compartilhamento, aprendizagem, captação de recursos e mobilização" (p. 28). Configurou-se recentemente 
fonte de pesquisa de diversos estudos que buscam analisar e compreender o comportamento individual e coletivo através das ações e interações na vida diária no ambiente virtual.

Buscando impulsionar a cadeia colaborativa de processos educativos, potencializando a troca do conhecimento, o uso das redes sociais tem apoiado um conjunto diverso de mediações nos contextos de aprendizagem. $\mathrm{O}$ acesso a essas redes não se constitui como um obstáculo a ser resolvido por restritos conhecimentos técnicos ou por seleção de atores. O envolvimento já ultrapassa os milhões de pessoas e se apresenta como um espaço em potencial para a prática pedagógica. As redes sociais educativas se propõem a "utilizar a tecnologia de análise da interação [...] para permitir a criação de comunidades com diferentes níveis de acesso que potencializem a interação entre pares e forneçam ajuda mútua para criar um ambiente favorável à aprendizagem" (GOMES, p. 242, 2011).

\section{Edmodo: uma rede social educativa}

O Edmodo é uma plataforma educativa de acesso livre e/ou versão paga, com interface comparada à microblogging, disponível em vários idiomas e dispõe de mecanismos que possibilitam a customização de cada usuário. O incentivo ao modelo de aprendizagem colaborativa é ressaltado pelas políticas de usabilidade da plataforma.

A organização das atividades dentro da interface espelha um procedimento relativamente intuitivo, no qual o gerenciamento das interações é beneficiado pelo design que se aproxima das redes sociais populares e direcionadas para outros fins. As atividades podem ser acompanhadas pelo mediador através de aplicativos complementares, possibilitando o monitoramento das atividades e eventuais interferências com ações. Permite ainda o compartilhamento em nuvem de diversos tipos de mídias e tem suporte para as tecnologias móveis.

\section{Uso do Edmodo sob a perspectiva da Social Network Analysis}

Estudos publicados sobre os ambientes virtuais de aprendizagem demonstram que a reconfiguração de mediações tradicionais em interfaces baseadas em redes sociais tem dinamizado as ações entre professores e estudantes, ampliando a interação, o comprometimento com os conteúdos, a troca de experiências e a resolução de problemas. Esse movimento acontece dentro da rede e condicionado aos direcionamentos dos mediadores. Sob tais aspectos, resolvemos criar um experimento voltado para projetos de pesquisa dentro da universidade.

Empregamos nesta investigação acadêmica desenvolvida no primeiro semestre de 2015, entre os meses de março a junho, o método técnico da pesquisa participante, aplicando e melhorando procedimentos desenvolvidos a partir da interação entre $10(\mathrm{dez})$ estudantes da graduação de Jornalismo em Multimeios, acompanhados por dois professores pesquisadores, na expectativa de impulsionar a utilização de ambientes virtuais de aprendizagem, que mais se aproximam das funcionalidades das redes sociais, por grupos de pesquisa. O processo de escolha da rede social Edmodo, utilizado na experiência, teve como pressuposto articular a capacidade dos discentes que participam do Projeto de Pesquisa Cartografia Urbanográfica do Sertão do São Francisco (CAUS) na interação com os materiais do acervo. Necessitávamos de uma relação mediada em espaço virtual para acesso a $e$-book, suporte para extensões variadas de arquivos de 
texto, áudio, vídeo e imagem. Também, organizamos um plano que necessitaria de ferramentas que contemplassem a construção de tarefas e enquetes. Outro aspecto requerido foi a possibilidade do armazenamento de conteúdos no próprio ambiente.

Ao implantar o ambiente junto às atividades do CAUS, começamos a explorar as possibilidades dos recursos da plataforma, adaptando algumas aplicações. As manobras investigativas partiram com base nos estudos da Social Network Analysis (SNA), métricas que possibilitam descrever e monitorar com potencial de abordagem ampla uma rede por meio da exploração de suas propriedades (Magdaleno et. al, 2010). Tais procedimentos permitiram vislumbrar um cenário favorável à mineração dos dados que identificaram os padrões das interações na rede social. Ações desenvolvidas potencializaram o interesse dos discentes durante a constituição da epistemologia do campo de pesquisa que estavam atuando.

A partir da SNA, escalamos a métrica Cohesion Degree para avaliar a coesão do grupo que criamos e montar indicadores do nível de interatividade. Percebemos que alguns membros não chegaram a publicar nenhum conteúdo e, portanto estava acarretando impacto negativo na coesão do grupo. Para ampliar os resultados da análise sobre o grupo, resolvemos aplicar outra métrica: a Visibility Degree. Ela nos permitiu alcançar os níveis de visibilidade e isolamentos de cada integrante dentro do grupo. Trata-se de trabalhar com o grau de centralidade apontando para a troca de informações e comunicação dos membros. A métrica Engagement cuidou de nos auxiliar em contabilizar o número de interações iniciadas pelos membros. Revelou, no momento, o quão ativo e central se mostrava dois ou três membros de um grupo de dez.

Percebíamos que o grupo estava com baixo índice de coesão, membros isolados e alguns com níveis de centralidade muito alta. Isso reforçou a descendente da exponencial engajamento, ou seja, baixo nível de interação entre os envolvidos. A estratégia para reconfigurar o grupo foi sugerir ao mediador a proposta de requisitar dos membros publicações onde indagavam sobre as leituras, ao tempo que tentassem responder as perguntas dos outros integrantes. A solicitação fomentou o debate na plataforma e provocou a interação entre $80 \%$ dos membros. Constatamos, posteriormente, em diálogo com os membros, que o acúmulo de atividades de outros componentes curriculares condicionava o acompanhamento dos recursos requisitados na plataforma. De modo que a maioria alegava falta de tempo para acessar e a ausência de um alerta para as novas atividades na plataforma. Incentivamos que todos instalassem o aplicativo do Edmodo em seus dispositivos móveis e o distanciamento com a ferramenta reduziu a quase zero.

\section{Análise dos resultados}

Com o auxílio da rede social Edmodo, o experimento constatou um contato mais frequente entre os membros do projeto de pesquisa CAUS - comparando com a quantidade de interações e reuniões desenvolvidas pelos grupos tradicionais proporcionando um maior interesse pela ciência, visto que o ambiente virtual tem possibilitado a utilização de um número grande de mídias e conteúdos diversos até então inacessíveis ao círculo de atuação dos investigados.

Ao tempo que intensificavam o uso do ambiente, os integrantes do projeto de pesquisa se mostravam mais atraídos e interessados em participar das discussões do 
grupo. As intervenções iluminadas pela SNA possibilitaram a reconstrução das práticas de pesquisa, de modo a permitir aos estudantes novas formas de buscar, interpretar, representar e compreender os conteúdos (PRADO, 2004).

A viabilidade dos procedimentos não se restringe às cognições individuais, preocupação inerente dos grupos de pesquisa que tendem a sucumbir pelo distanciamento entre os pesquisadores. Ao contrário, nosso experimento detectou, a partir das observações, um aumento dos níveis de colaboração nas atividades requisitadas pelo mediador. $\mathrm{O}$ reconhecimento como um protagonista do processo desenvolve nos membros um senso de responsabilidade que, consequentemente, funciona como um estímulo para a investigação e análise dos problemas. Nesse sentido, a inovação parece condicionar certas situações; as quais seriam impossibilitadas de resolver subtraídas à tecnologia.

A emancipação da ciência exige novos olhares sobre suas práticas e constante revisão de métodos. Portanto, engrandecer o protagonismo dos jovens pesquisadores, apresentando uma ciência atenta aos processos tecnológicos que lhes cerca, gera posicionamentos capazes de romper com a mais complexa dificuldade que uma academia possa agregar. A autonomia crítica dos membros da pesquisa na tomada de decisões e o manejo sobre as informações alocadas encurtam as adversidades e potencializam a construção coletiva do saber.

\section{Referências}

Amorim, Ricardo [et al.]. (2013) "Architecture for Social Interactions Monitoring in Collaborative Learning", http://ieeexplore.ieee.org/stamp/stamp.jsp?tp=\&arnumber=6601884. Abril.

Gomes, Alex S. [et al.]. Hipertexto e cibercultura: links com literatura, publicidade, plágio e redes sociais. São Paulo: Respel, 2011.

Magdaleno, Andréa; Werner, Cláudia; Araujo, Renata. Estudo de Ferramentas de Mineração, Visualização e Análise de Redes Sociais. Rio de Janeiro: PESC-COPPE, 2010 .

Marteleto, Regina M. (2010) "Redes sociais, mediação e apropriação de informações: situando campos, objetos e conceitos na pesquisa em Ciência da Informação", Pesq. Bras. Ci. Inf., IBICT, Brasília, v.3, n.1, p.27-46.

Prado, Maria E. B. B. e Schlunzen Junior, Klaus. Integração de mídias digitais na educação. São Paulo: PUC, 2004.

Recuero, Raquel. Redes Sociais na internet. Porto Alegre: Sulina, 2009.

Serrão, Tassia [et al.]. (2012) "Uma Arquitetura baseada em Web Services para Software Social Móvel”, http://ieeexplore.ieee.org/stamp/stamp.jsp?arnumber=6218017, Maio. 